\section{(6) OPEN ACCESS}

\title{
Population and dyadic-based seroincidence of herpes simplex virus- 2 and syphilis in southern India
}

\author{
Chad H Hochberg, ${ }^{1}$ John A Schneider, ${ }^{2}$ Rakhi Dandona, ${ }^{3}$ Vemu Lakshmi, ${ }^{4}$ \\ G Anil Kumar, ${ }^{3}$ Talasila Sudha, ${ }_{1}^{4}$ Mohammed Akbar, ${ }^{3}$ G Md Mushtaq Ahmed, ${ }^{3}$ \\ Sri P Ramgopal, ${ }^{3}$ Benjamin Armbruster, ${ }^{5}$ Michel Alary, ${ }_{1}^{6}$ Lalit Dandona ${ }^{3,7}$
}

\begin{abstract}
- Additional material is published online only. To view please visit the journal online (http://dx.doi.org/10.1136/ sextrans-2014-051708).

${ }^{1}$ Pritzker School of Medicine, University of Chicago Chicago, Illinois, USA

${ }^{2}$ Department of Medicine and Chicago Center for HIV Elimination, University of Chicago, Chicago, Illinois, USA ${ }^{3}$ Public Health Foundation of India, New Delhi, India

${ }^{4}$ Department of Microbiology, Nizam's Institute of Medical Sciences, Hyderabad, India ${ }^{5}$ Department of Engineering, Northwestern University, Chicago, Illinois, USA

${ }^{6}$ Département de médecine sociale et préventive, URESP Centre de recherche du CHU de Québec, Université Laval, Québec, Canada

${ }^{7}$ Institute for Health Metrics and Evaluation, University of Washington, Seattle, Washington, USA
\end{abstract}

\section{Correspondence to} Dr John A Schneider, 5841 South Maryland Avenue, MC 5065, University of Chicago Medicine, Chicago, IL 60637, USA; jschnei1@medicine.bsd. uchicago.edu

Received 1 June 2014 Revised 18 December 2014 Accepted 24 December 2014 Published Online First 20 January 2015
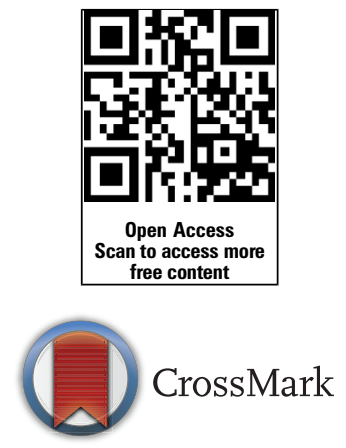

To cite: Hochberg $\mathrm{CH}$, Schneider JA, Dandona R, et al. Sex Transm Infect 2015;91:375-382.

\section{ABSTRACT}

Objectives Herpes simplex virus-2 (HSV-2) and syphilis are associated with increased risk of HIV, highlighting the importance of understanding their transmission dynamics. In India, most studies of HSV-2 and syphilis incidence are in high-risk populations and may not accurately reflect infectious activity. In this study, we aim to define HSV-2/syphilis incidence and risk factors in a population sample.

Methods We conducted a longitudinal population-based survey in Andhra Pradesh, India, in two rounds: 2004-2005 and 2010-2011. Sociodemographic and behavioural data were collected, and dried blood spots tested for HSV-2 and Treponema pallidum IgG. After calculating sexually transmitted infection (STI) incidence, associated factors were assessed using modified Poisson regression and within-couple transmission rates modelled using seroconcordance/discordance data.

Results 12617 adults participated at baseline with 8494 at follow-up. Incidence of HSV-2 and syphilis per 1000 person-years was $25.6(95 \% \mathrm{Cl} 24.1$ to 27.2$)$ and 3.00 ( $95 \% \mathrm{Cl} 2.52$ to 3.54). Incidence of HSV-2 was higher in women vs men (31.1 vs 20.2$)$ and in rural vs urban residents (31.1 vs 19.0) ( $p<0.05$ for both). STI seroincidence increased in a step-wise fashion with age and was associated with spousal seropositivity for both sexes (incidence rate ratio (IRR) 2.59 to 6.78). Within couples the rate of transmission per 1000 couple-years from men to women vs women to men was higher for HSV-2 (193.3 vs 119.0) compared with syphilis (27.6 vs 198.8), $p<0.05$ for both.

Conclusions HSV-2 has higher incidence among subpopulations such as women, rural residents and olderaged individuals, suggesting a need for more generalised STI prevention approaches among populations traditionally considered low risk.

\section{INTRODUCTION}

In India, previous work has indicated a high burden of sexually transmitted infections (STIs) and a rising prevalence of genital ulcerative diseases including herpes simplex virus-2 (HSV-2) and syphilis. ${ }^{1}{ }^{2}$ In addition to the significant morbidity resulting directly from these infections, both HSV-2 and syphilis are associated with an increased risk of HIV, and specifically a high population attributable risk for HIV in India. ${ }^{3-6}$ This highlights the need to better understand the epidemiology of these infections in India.

Existing Indian prevalence data for HSV-2 and syphilis have shown marked geographic and gendered heterogeneity. Estimates from populationbased serostudies have ranged from $5.87 \%$ to $18.9 \%$ for HSV-2 and $0.4-1.7 \%$ for syphilis. ${ }^{7-10}$ These estimates have suggested higher HSV-2 prevalence in women and have shown inconsistent urban versus rural patterning. Incidence studies of these STIs in India have come from high-risk populations and may not accurately reflect disease transmission. HSV-2 incidence estimates have ranged from an annualised $8 \%$ to 15.1 per 100 personyears, ${ }^{4} 1112$ which are relatively higher rates than estimates from Western countries. ${ }^{13}{ }^{14}$ Syphilis incidence estimates have ranged from 5.4 per 100 person-years to an annualised incidence of $1 \%$ and $5 \%$ for men and women, respectively. ${ }^{5} 12$

Population-based studies have been proposed as providing more reliable estimates of true population disease rates. ${ }^{15}{ }^{16}$ Furthermore, examinations of transmission within couples can aid in our understanding of transmission dynamics. ${ }^{17}$ Taken together such studies can help to provide a better foundation for effective HIV/STI prevention strategies.

Here we report data from a longitudinal population-based study of HIV, HSV-2 and syphilis incidence from the south Indian state of Andhra Pradesh. ${ }^{18}$ Andhra Pradesh is thought to have the highest HIV burden in India and is also reported to have high rates of HSV-2. ${ }^{10}{ }^{15}$ In addition to calculating incidence, we also examined associated risk factors and seroconcordance/discordance patterns among stably married couples.

\section{METHODS}

\section{Study population and setting}

We conducted a longitudinal population-based survey in two rounds over 5.6 years: round 1 was conducted between September 2004 and September 2005 and round 2 between May 2010 and July $2011 .{ }^{18}$ The original study design, baseline findings and HIV incidence have been described in detail elsewhere. ${ }^{15} 1819$ In brief, at baseline, persons 1549 years old were selected using a stratified random sampling method to construct a representative sample of the adult population of Guntur district in Andhra Pradesh. Of the 13838 eligible people identified at baseline, 12617 (91.2\%) participated.

For round 2 data collection, interviewers returned to each household and invited subjects to participate in the follow-up survey. ${ }^{18}$ At least five attempts were made to contact each eligible participant, including tracking and contacting those that 
had moved. Of the 12557 non-homeless participants at baseline, $7222(57.5 \%)$ had remained at the same residence (including 229 who had died) and 5335 (42.5\%) had moved. Of those who had moved, $3562(66.8 \%)$ were traced and contacted.

\section{Interviews}

Trained interviewers conducted confidential interviews to assess sociodemographic and behavioural characteristics. ${ }^{18}$ Sociodemographic information from the interviews included age, sex, residence (rural vs urban), education, caste, religion, marital status, occupation and standard of living index (SLI). ${ }^{15}$ Information on risk behaviour included number of lifetime sexual partners, condom use, alcohol and tobacco use, transfusion history and same-sex activity (for men).

\section{Blood samples}

A finger prick method was used to obtain a dried blood spot (DBS) on Whatman No. 3 paper (Whatman International, Maidstone, UK). Lifetime prevalence of HSV-2 and syphilis was evaluated by testing for the presence of HSV-2 IgG (HerpeSelect 2 ELISA IgG, Focus Diagnostics, California, USA) using an index value of $>1.1,{ }^{20}$ and Treponema pallidum IgG (Treponostika sandwich ELISA, bioMérieux, France). ${ }^{21}$ For quality control, DBSs were compared with standard serum testing of 75 samples from an STD clinic and demonstrated $100 \%$ specificity and sensitivity. Additionally, all positive DBSs were retested and $10 \%$ of negative samples were retested, yielding $100 \%$ concordance with the original results.

\section{HSV-2 and syphilis incidence analyses}

Factors associated with participation status at follow-up were analysed using $\chi^{2}$ and $t$ tests. Incident cases of HSV-2/syphilis were defined as seroconversion from negative to positive in an analytic sample of those who were HSV-2/syphilis seronegative at baseline. Total person-time was calculated as the sum of the follow-up periods of each participant and was used as the denominator for the incidence calculation. Since the exact time of infection was unknown, infection was estimated to have occurred at the midway point of the study, and those with incident STIs contributed half of their total follow-up time to total person-years. $^{22}$

Factors associated with STI incidence were assessed using modified Poisson regressions with robust error estimation in a multistep process. ${ }^{23}$ First, we used univariate regression to examine the association of each variable with incident infection. Then we included all variables significant at the $\mathrm{p}<0.10$ level from the univariate models in a multivariable regression that was then followed by backwards elimination to select variables remaining significant at the $\mathrm{p}<0.05$ level. Sociodemographic and risk multivariable models were built and examined separately in order not to underestimate the effect of factors more distally related to infection (ie, rural residence vs number of lifetime sex partners) and then combined into a final model. ${ }^{9} 101924$ Analyses were done using STATAV.12.0 (StataCorp, Austin, Texas, USA).

\section{HSV-2 and syphilis dyadic transmission analysis}

Raw transmission rates between couples were compared using tests of proportions. In order to examine transmission dynamics, we built a Markov model with four states corresponding to the possible serostatuses of couples: (1) negatively concordant, male (M)-, female (F)-; (2) male positive discordant, $\mathrm{M}+, \mathrm{F}-$; (3) female positive discordant, $\mathrm{M}-, \mathrm{F}+$; and (4) positively concordant, $\mathrm{M}+, \mathrm{F}+$. We let $\alpha$ be the rate at which the man is infected outside the couple; $\beta$ the rate that the woman is infected outside the couple; $\delta$ the rate of male-to-female transmission within the couple; and $\gamma$ the rate of female-to-male transmission within the couple. Thus the transition rate from state $1->2$ is $\alpha ; 1->3$ is $\beta ; 2->4$ is $\beta+\delta$; and $3->4$ is $\alpha+\gamma$. Then over a $\mathrm{T}=5$-year period, the transition probabilities between states are $\mathrm{P}_{11}=\mathrm{e}^{-(\alpha+\beta) \mathrm{T}}, \quad \mathrm{P}_{12}=\left(\mathrm{e}^{-(\alpha+\beta) \mathrm{T}}-\mathrm{e}^{-(\beta+\delta) \mathrm{T}}\right) \alpha /$ $(\delta-\alpha), \quad \mathrm{P}_{13}=\left(\mathrm{e}^{-(\alpha+\beta) \mathrm{T}}-\mathrm{e}^{-(\alpha+\gamma) \mathrm{T}}\right) \beta /(\gamma-\beta), \quad \mathrm{P}_{14}=1-\mathrm{P}_{11}-\mathrm{P}_{12}-\mathrm{P}_{13}$, $\mathrm{P}_{22}=\mathrm{e}^{-(\beta+\delta) \mathrm{T}}, \quad \mathrm{P}_{24}=1-\mathrm{e}^{-(\beta+\delta) \mathrm{T}}, \quad \mathrm{P}_{33}=\mathrm{e}^{-(\alpha+\gamma) \mathrm{T}}, \quad \mathrm{P}_{34}=1-\mathrm{e}^{-(\alpha+\gamma) \mathrm{T}}$. Let $n_{i j}$ be the number of couples observed in state $i$ at baseline and state $\mathrm{j}$ at follow-up. The log likelihood is then $\sum_{\mathrm{ij}} \mathrm{n}_{\mathrm{ij}} \log$ $\left(\mathrm{P}_{\mathrm{ij}}\right)$. For both HSV-2 and syphilis, we then estimated the parameters $\alpha, \beta, \delta$ and $\gamma$ using maximum likelihood estimation. CIs were calculated using the likelihood ratio test.

\section{RESULTS}

\section{Study participants}

Of 12617 baseline participants, 8362 (66.3\%) provided a blood spot and follow-up interview. Of this sample, 4593 (54.1\%) were rural residents and 4358 (51.3\%) women. Lower participation at follow-up was associated with baseline HIV/ HSV-2 but not syphilis seropositivity (HSV-2(+) 63.7 vs HSV-2 (-) 67.6\%, p=0.01; $\mathrm{HIV}(+) 43.1$ vs $\mathrm{HIV}(-) 67.8 \%, \mathrm{p}<0.001$; syphilis(+) 61.4 vs syphilis(-) $66.4 \%, p=0.12)$. Women and rural residents were more likely to participate $(68.3 \%$ women vs $66.3 \%$ men, $\mathrm{p}=0.02)(72.7 \%$ rural vs $62.5 \%$ urban, $\mathrm{p}<0.001)$. Women that participated were older than women who did not (mean (SD) 30.2 (9.5) years at baseline vs 28.8 (10.0), $\mathrm{p}<0.001)$.

Of the 4358 women in the final sample, 389 (8.9\%) were HSV-2 seropositive and 54 (1.2\%) syphilis seropositive at baseline. This yielded final female analytic samples of 3969 for HSV-2 and 4304 for syphilis. Of the 4136 men in the final sample, 213 (5.1\%) were HSV-2 and 84 (2.0\%) syphilis seropositive at baseline and were excluded from further analysis. This yielded final male analytic samples of 3923 for HSV-2 and 4052 for syphilis.

\section{Seroincidence}

Over a mean follow-up time of 5.63 years (range 5.17-6.33), the incidence per 1000 person-years for HSV-2 and syphilis was 25.6 (95\% CI 24.1 to 27.2 ) and 3.00 (95\% CI 2.52 to 3.54 ) (table 1).

The incidence of HSV-2 was higher in women than men (31.1 vs 20.2 per 1000 person-years, $\mathrm{p}<0.001$ ) and higher in rural than urban residents (31.1 vs 19.0 per 1000 person-years, $\mathrm{p}<0.001)$. The incidence of syphilis in men vs women was not statistically significant (3.22 vs 2.79 per 1000 person-years, $\mathrm{p}=0.39$ ), while rural vs urban syphilis incidence was borderline (3.44 vs 2.48 per 1000 person-years, $\mathrm{p}=0.06$ ). Both HSV-2 and syphilis incidence increased with age, and this was consistent for both men and women ( $p$-trend $<0.05$, see online supplementary figure S1).

\section{Factors associated with infection}

For HSV-2 and syphilis, the univariate and final combined multivariate analyses are presented in table 2 for men and in table 3 for women. Only factors that were included in the sociodemographic and health/behavioural multivariate models (significant at the $\mathrm{p}<0.05$ level in these models) are shown here. Please refer to online supplementary tables S1 and S2 for a full reporting of all factors that were considered.

For men, sociodemographic factors associated with higher HSV-2 incidence in univariate analyses were increasing age, rural residence, transport-related occupation, lower caste, 
Table 1 Seroincidence and seroprevalence of herpes simplex virus-2 (HSV-2) and syphilis by age and residence

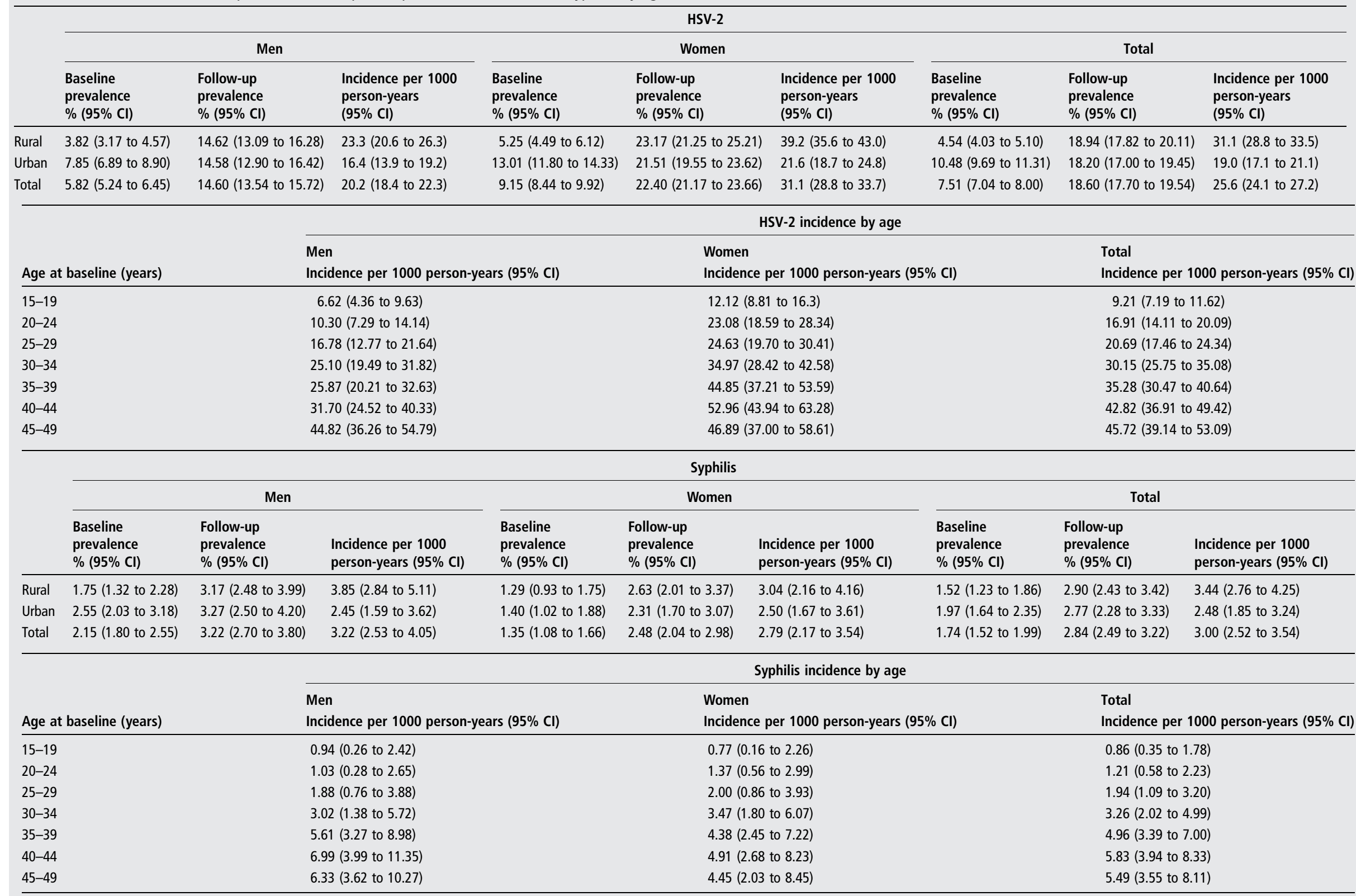


Table 2 Behavioural and sociodemographic associations with incident herpes simplex virus-2 (HSV-2) or syphilis infection in men ( $\mathrm{n}=4136$ )

\begin{tabular}{|c|c|c|c|c|c|c|}
\hline \multirow[b]{2}{*}{ Variable } & \multicolumn{3}{|l|}{ HSV-2 } & \multicolumn{3}{|l|}{ Syphilis } \\
\hline & $\begin{array}{l}\% \text { Seroconversions } \\
(\mathrm{N})^{*}\end{array}$ & $\begin{array}{l}\text { Univariate } \\
\text { associations } \\
\text { IRR }(95 \% \mathrm{Cl})\end{array}$ & $\begin{array}{l}\text { Combined multivariate model } \\
\text { adjusted IRR }(95 \% \mathrm{CI})\end{array}$ & $\begin{array}{l}\text { Percentage } \\
\text { positive (N) }\end{array}$ & $\begin{array}{l}\text { Univariate } \\
\text { associations } \\
\text { IRR }(95 \% \mathrm{CI})\end{array}$ & $\begin{array}{l}\text { Combined } \\
\text { multivariate model } \\
\text { adjusted IRR }(95 \% \mathrm{Cl})\end{array}$ \\
\hline Overall: & $10.81(3923)$ & - & - & $1.80(4052)$ & - & - \\
\hline \multicolumn{7}{|l|}{ Sociodemographics } \\
\hline \multicolumn{7}{|l|}{ Age at baseline (years) } \\
\hline $15-19$ & $3.66(737)$ & 1.00 & 1.00 & $0.53(753)$ & 1.00 & 1.00 \\
\hline $20-24$ & $5.65(672)$ & $1.56(0.95$ to 2.55$)$ & 1.34 (0.79 to 2.28$)$ & $0.58(687)$ & $1.09(0.27$ to 4.38$)$ & $0.55(0.14$ to 2.14$)$ \\
\hline $25-29$ & $9.05(652)$ & 2.53 (1.61 to 4.00 ) & 2.07 (1.18 to 3.65$)$ & $1.06(662)$ & $1.99(0.58$ to 6.81$)$ & 0.82 (0.23 to 2.96$)$ \\
\hline $30-34$ & $13.23(514)$ & 3.79 (2.43 to 5.92$)$ & 2.78 (1.58 to 4.88$)$ & $1.69(533)$ & 3.19 (0.98 to 10.37$)$ & $1.19(0.34$ to 4.12$)$ \\
\hline $35-39$ & $13.60(522)$ & 3.91 (2.51 to 6.08 ) & 2.82 (1.60 to 4.96$)$ & $3.11(546)$ & 5.94 (2.00 to 17.65$)$ & 2.20 (0.68 to 7.07$)$ \\
\hline $40-44$ & $16.42(402)$ & 4.79 (3.06 to 7.49$)$ & 3.37 (1.90 to 5.95$)$ & $3.86(414)$ & 7.40 (2.47 to 22.14$)$ & 2.78 (0.86 to 9.01$)$ \\
\hline $45-49$ & $22.41(424)$ & 6.77 (4.42 to 10.37$)$ & 4.79 (2.75 to 8.33$)$ & $3.50(457)$ & 6.70 (2.24 to 20.04$)$ & 2.47 (0.74 to 8.29$)$ \\
\hline \multicolumn{7}{|l|}{ Place of residence } \\
\hline Urban & 8.85 (1728) & 1.00 & 1.00 & $1.37(1821)$ & 1.00 & - \\
\hline Rural & 12.35 (2195) & 1.42 (1.17 to 1.73$)$ & 1.30 (0.90 to 1.78$)$ & $2.15(2231)$ & 1.57 (0.97 to 2.55$)$ & - \\
\hline \multicolumn{7}{|l|}{ Standard of living index } \\
\hline $0-16$ & $12.51(983)$ & 1.00 & - & $2.00(1000)$ & 1.00 & 1.00 \\
\hline $17-22$ & $9.90(1040)$ & 0.78 (0.60 to 1.02$)$ & - & $2.50(1082)$ & 1.25 (0.70 to 2.23$)$ & 1.31 (0.73 to 2.35$)$ \\
\hline $23-29$ & 10.95 (1023) & 0.87 (0.68 to 1.13$)$ & - & $1.78(1069)$ & 0.89 (0.48 to 1.67$)$ & $0.96(0.50$ to 1.82$)$ \\
\hline $30-54$ & $9.81(877)$ & 0.78 (0.59 to 1.02 ) & - & $0.78(901)$ & 0.39 (0.16 to 0.92$)$ & 0.44 (0.18 to 1.07$)$ \\
\hline \multicolumn{7}{|l|}{ Education } \\
\hline None & $14.31(1027)$ & 1.00 & 1.00 & $3.04(1054)$ & 1.00 & - \\
\hline Class 1-10 & 10.75 (2149) & 0.74 (0.60 to 0.90$)$ & $0.93(0.75$ to 1.15$)$ & $1.48(2227)$ & $0.48(0.30$ to 0.79$)$ & - \\
\hline Class 11-12 & $5.25(305)$ & $0.35(0.21$ to 0.58$)$ & 0.57 (0.34 to 0.97$)$ & $0.94(319)$ & $0.31(0.90$ to 1.00$)$ & - \\
\hline Technical school/college & $6.80(441)$ & 0.46 (0.31 to 0.68$)$ & 0.71 (0.47 to 1.07 ) & $1.11(451)$ & $0.36(0.14$ to 0.93$)$ & - \\
\hline \multicolumn{7}{|l|}{ Occupation } \\
\hline Other & $10.48(3656)$ & 1.00 & 1.00 & $1.64(3779)$ & 1.00 & 1.00 \\
\hline Transport related & $15.36(267)$ & 1.49 (1.08 to 2.06$)$ & 1.27 (0.90 to 1.78$)$ & $4.03(273)$ & 2.47 (1.30 to 4.69$)$ & 2.01 (1.04 to 3.89 ) \\
\hline \multicolumn{7}{|l|}{ Caste } \\
\hline Forward caste & 10.03 (1376) & 1.00 & 1.00 & $1.54(1426)$ & 1.00 & - \\
\hline Backward caste & $11.05(977)$ & 1.11 (0.86 to 1.42$)$ & 1.15 (0.89 to 1.49$)$ & 2.20 (999) & $1.43(0.79$ to 2.58$)$ & - \\
\hline Scheduled caste & $13.36(846)$ & 1.34 (1.05 to 1.72$)$ & 1.57 (1.08 to 2.28$)$ & $1.83(875)$ & $1.18(0.62$ to 2.24$)$ & - \\
\hline Scheduled tribe & $9.70(133)$ & 0.97 (0.55 to 1.71$)$ & 1.01 (0.56 to 1.80$)$ & $2.19(137)$ & $1.43(0.43$ to 4.78$)$ & - \\
\hline Not applicable & $8.81(590)$ & 0.87 (0.63 to 1.20$)$ & 2.10 (1.10 to 4.01$)$ & $1.63(615)$ & $1.05(0.50$ to 2.22$)$ & - \\
\hline \multicolumn{7}{|l|}{ Religiont } \\
\hline Hindu & $11.03(2503)$ & 1.00 & 1.00 & $1.82(2580)$ & 1.00 & - \\
\hline Muslim & 7.89 (596) & 0.70 (0.52 to 0.96$)$ & $0.44(0.22$ to 0.84$)$ & $1.60(626)$ & $0.88(0.44$ to 1.73$)$ & - \\
\hline Christian & $12.30(821)$ & 1.12 (0.89 to 1.40$)$ & $0.82(0.57$ to 1.17$)$ & $1.90(83)$ & 1.04 (0.59 to 1.83$)$ & - \\
\hline Other & $0(3)$ & - & - & $0(3)$ & - & - \\
\hline \multicolumn{7}{|l|}{ Marital status } \\
\hline Never & $3.66(1065)$ & 1.00 & - & $0.46(1085)$ & 1.00 & - \\
\hline Currently & $13.45(2802)$ & 3.87 (2.79 to 5.38 ) & - & $2.30(2908)$ & 5.05 (2.04 to 12.54$)$ & - \\
\hline Previously & $14.29(56)$ & 4.13 (1.93 to 8.82 ) & - & $1.69(59)$ & 3.71 (0.43 to 31.8 ) & - \\
\hline \multicolumn{7}{|l|}{ Health behaviours } \\
\hline \multicolumn{7}{|l|}{ Circumcision‡ } \\
\hline No & 11.30 (3229) & 1.00 & - & $1.84(3320)$ & 1.00 & - \\
\hline Yes & $8.72(654)$ & 0.76 (0.58 to 1.01$)$ & - & $1.74(691)$ & 0.95 (0.51 to 1.76$)$ & - \\
\hline \multicolumn{7}{|l|}{ Alcohol history } \\
\hline Never & 8.56 (2092) & 1.00 & 1.00 & $1.11(2156)$ & 1.00 & - \\
\hline Currently & $12.76(1552)$ & 1.52 (1.24 to 1.86$)$ & 1.03 (0.83 to 1.29$)$ & $2.62(1603)$ & 2.37 (1.44 to 3.91$)$ & - \\
\hline Previously & $16.97(277)$ & 2.08 (1.51 to 2.86$)$ & 1.35 (0.97 to 1.88$)$ & $2.41(291)$ & 2.18 (0.94 to 5.04$)$ & - \\
\hline \multicolumn{7}{|l|}{ Sexual behaviour } \\
\hline Lifetime female sex partner & & & & & & \\
\hline 0 & $3.67(817)$ & 1.00 & 1.00 & $0.24(833)$ & 1.00 & 1.00 \\
\hline 1 & $8.82(1089)$ & 2.46 (1.63 to 3.71$)$ & $0.96(0.57$ to 1.60$)$ & $0.71(1122)$ & 2.97 (0.63 to 14.00$)$ & $1.70(0.31$ to 9.20$)$ \\
\hline$>1$ & $14.94(1975)$ & 4.32 (2.97 to 6.29$)$ & 1.38 (0.83 to 2.31$)$ & 3.07 (2054) & 12.97 (3.17 to 53.02$)$ & 5.97 (1.30 to 27.32$)$ \\
\hline HSV-2/syphilis-positive spo & & & & & & \\
\hline No & $9.97(3782)$ & 1.00 & 1.00 & $1.69(4029)$ & 1.00 & 1.00 \\
\hline Yes & $33.33(141)$ & 3.80 (2.82 to 5.12$)$ & 2.59 (1.89 to 3.55$)$ & $21.74(23)$ & 14.54 (5.90 to 35.82$)$ & 6.78 (2.52 to 18.21$)$ \\
\hline
\end{tabular}

*Seroconversion from negative to positive over study duration.

tFor religion 'other' category excluded from regressions because of sample size.

‡Circumcision excluded from final model because of collinearity with Muslim religion.

SHSV-2 positive spouse included in HSV-2 model and syphilis-positive spouse included in syphilis model.

HSV-2, herpes simplex virus-2; IRR, incident rate ratio; N, total number of people (positive and negative) in category. 
Table 3 Behavioural and sociodemographic associations with incident HSV-2 or syphilis infection in women ( $\mathrm{n}=4358$ )

\begin{tabular}{|c|c|c|c|c|c|c|}
\hline \multirow[b]{2}{*}{ Variable } & \multicolumn{3}{|l|}{ HSV-2 } & \multicolumn{3}{|l|}{ Syphilis } \\
\hline & $\begin{array}{l}\% \text { Seroconversions } \\
(\mathrm{N})^{*}\end{array}$ & $\begin{array}{l}\text { Univariate } \\
\text { associations } \\
\text { IRR }(95 \% \mathrm{Cl})\end{array}$ & $\begin{array}{l}\text { Combined multivariate } \\
\text { model adjusted } \\
\text { IRR }(95 \% \mathrm{Cl})\end{array}$ & $\begin{array}{l}\text { Percentage } \\
\text { positive }(\mathrm{N})\end{array}$ & $\begin{array}{l}\text { Univariate } \\
\text { associations } \\
\text { IRR }(95 \% \mathrm{CI})\end{array}$ & $\begin{array}{l}\text { Combined multivariate } \\
\text { model adjusted } \\
\text { IRR }(95 \% \mathrm{CI})\end{array}$ \\
\hline Overall & 16.10 (3969) & - & - & $1.56(4304)$ & - & - \\
\hline \multicolumn{7}{|l|}{ Sociodemographics } \\
\hline \multicolumn{7}{|l|}{ Age at baseline (years) } \\
\hline $15-19$ & $6.61(666)$ & 1.00 & 1.00 & $0.43(690)$ & 1.00 & 1.00 \\
\hline $20-24$ & $12.20(746)$ & 1.90 (1.33 to 2.73$)$ & $1.46(1.01$ to 2.11$)$ & $0.77(780)$ & $1.77(0.44$ to 7.09$)$ & 1.52 (0.38 to 6.18$)$ \\
\hline $25-29$ & $12.93(665)$ & 2.03 (1.41 to 2.92 ) & $1.52(1.04$ to 2.21$)$ & $1.11(718)$ & $2.58(0.68$ to 9.73$)$ & 2.22 (0.60 to 8.33$)$ \\
\hline $30-34$ & $17.90(553)$ & $2.88(2.02$ to 4.11$)$ & 2.02 (1.39 to 2.92$)$ & $1.94(620)$ & 4.49 (1.27 to 15.92$)$ & 3.31 (0.92 to 11.83$)$ \\
\hline $35-39$ & $22.37(541)$ & 3.70 (2.62 to 5.22 ) & 2.52 (1.75 to 3.64$)$ & $2.43(617)$ & 5.66 (1.64 to 19.56$)$ & 3.83 (1.09 to 13.48$)$ \\
\hline $40-44$ & $25.91(467)$ & 4.37 (3.10 to 6.16$)$ & 3.02 (2.09 to 4.37$)$ & $2.72(514)$ & 6.34 (1.82 to 22.08$)$ & 4.44 (1.26 to 15.62$)$ \\
\hline $45-49$ & $23.26(331)$ & 3.87 (2.67 to 5.60$)$ & 2.74 (1.85 to 4.07$)$ & $2.47(365)$ & 5.75 (1.56 to 21.25$)$ & 4.33 (1.18 to 15.94$)$ \\
\hline \multicolumn{7}{|l|}{ Place of residence } \\
\hline Urban & $11.41(1771)$ & 1.00 & 1.00 & $1.39(2012)$ & 1.00 & - \\
\hline Rural & $19.88(2198)$ & 1.82 (1.54 to 2.14$)$ & 1.45 (1.21 to 1.72$)$ & $1.70(2292)$ & 1.22 (0.75 to 1.98$)$ & - \\
\hline \multicolumn{7}{|l|}{ Standard of living index } \\
\hline $0-16$ & 21.05 (1045) & 1.00 & 1.00 & $2.03(1134)$ & 1.00 & - \\
\hline $17-22$ & $16.73(1034)$ & 0.78 (0.64 to 0.95$)$ & $0.86(0.70$ to 1.05$)$ & $2.14(1122)$ & $1.06(0.60$ to 1.88$)$ & - \\
\hline $23-29$ & $14.19(1001)$ & 0.65 (0.53 to 0.80$)$ & $0.79(0.63$ to 0.98$)$ & $1.09(1096)$ & $0.54(0.27$ to 1.09$)$ & - \\
\hline $30-54$ & $11.70(889)$ & 0.53 (0.42 to 0.67$)$ & $0.74(0.57$ to 0.96$)$ & $0.84(952)$ & $0.42(0.19$ to 0.93$)$ & - \\
\hline \multicolumn{7}{|l|}{ Educationt } \\
\hline None & $21.33(1791)$ & 1.00 & 1.00 & $2.50(1957)$ & 1.00 & 1.00 \\
\hline Any schooling & - & - & - & $0.77(2347)$ & $0.30(0.18$ to 0.52$)$ & $0.40(0.23$ to 0.70$)$ \\
\hline Class $1-10$ & $13.28(1800)$ & $0.59(0.50$ to 0.70$)$ & $0.86(0.71$ to 1.03$)$ & $0.77(1952)$ & - & - \\
\hline Class 11-12 & $4.89(184)$ & 0.21 (0.11 to 0.41$)$ & $0.45(0.23$ to 0.90$)$ & $1.06(189)$ & - & - \\
\hline Technical school/college & 4.64 (194) & 0.20 (0.10 to 0.38$)$ & $0.44(0.22$ to 0.88$)$ & $0.49(206)$ & - & - \\
\hline \multicolumn{7}{|l|}{ Occupation } \\
\hline Other & $15.83(3916)$ & 1.00 & 1.00 & $1.51(4243)$ & 1.00 & - \\
\hline Field related & $35.85(53)$ & 2.54 (1.63 to 3.97$)$ & 1.84 (1.12 to 3.02$)$ & $4.92(61)$ & 3.21 (1.04 to 10.57) & - \\
\hline \multicolumn{7}{|l|}{ Religion $\neq$} \\
\hline Hindu & $15.90(2554)$ & 1.00 & 1.00 & $1.62(2774)$ & 1.00 & - \\
\hline Muslim & $9.53(577)$ & $0.58(0.44$ to 0.77$)$ & $0.60(0.45$ to 0.80$)$ & $1.45(622)$ & 0.89 (0.44 to 1.83$)$ & - \\
\hline Christian & $21.34(834)$ & 1.37 (1.15 to 1.64$)$ & 1.23 (1.03 to 1.48$)$ & $1.44(904)$ & $0.88(0.47$ to 1.63$)$ & - \\
\hline Other & $0(4)$ & - & - & $0(4)$ & - & - \\
\hline \multicolumn{7}{|l|}{ Marital status } \\
\hline Never married & $2.53(356)$ & 1.00 & 1.00 & $0(367)$ & - & - \\
\hline Currently marred & 16.30 (3288) & 6.98 (3.61 to 13.48$)$ & 2.86 (1.42 to 5.77$)$ & $1.64(3542)$ & 1.00 & - \\
\hline Previously married & $38.92(325)$ & 13.28 (6.71 to 26.28$)$ & 4.35 (2.07 to 9.14$)$ & 2.28 (395) & $1.40(0.69$ to 2.82$)$ & - \\
\hline \multicolumn{7}{|l|}{ Health behaviour } \\
\hline \multicolumn{7}{|l|}{ History of tattoo } \\
\hline No & $15.80(3356)$ & 1.00 & 1.00 & $1.43(3627)$ & 1.00 & - \\
\hline Yes & $21.70(613)$ & 1.51 (1.25 to 1.82$)$ & $0.98(0.80$ to 1.20$)$ & $2.22(677)$ & 1.57 (0.88 to 2.78$)$ & - \\
\hline \multicolumn{7}{|l|}{ Chew or smoke tobacco } \\
\hline Never & $16.01(3847)$ & 1.00 & - & $1.44(4170)$ & 1.00 & 1.00 \\
\hline Ever & $18.85(122)$ & 1.21 (0.80 to 1.83$)$ & - & $5.22(134)$ & 3.74 (1.71 to 8.17$)$ & 1.83 (0.79 to 4.22$)$ \\
\hline \multicolumn{7}{|l|}{ Sexual behaviour } \\
\hline \multicolumn{7}{|l|}{ Lifetime male sex partners§ી } \\
\hline 0 & $2.77(325)$ & 1.00 & - & 0 (335) & 1.00 & 1.00 \\
\hline 1 & $16.04(3242)$ & 6.25 (3.23 to 12.08$)$ & - & $1.54(3516)$ & & \\
\hline$>1$ & $30.28(317)$ & 12.68 (6.41 to 25.09$)$ & - & $3.05(361)$ & 2.15 (1.12 to 4.09$)$ & $1.64(0.85$ to 3.18$)$ \\
\hline \multicolumn{7}{|l|}{ Syphilis/HSV-2 serostatus } \\
\hline Negative & 15.99 (3940) & 1.00 & 1.00 & $1.47(3940)$ & 1.00 & - \\
\hline Positive & $31.03(29)$ & $2.10(1.10$ to 4.01$)$ & $1.27(0.61$ to 2.65$)$ & $2.47(364)$ & $1.69(0.84$ to 3.40$)$ & - \\
\hline \multicolumn{7}{|c|}{ HSV-2/syphilis-positive spouse* * } \\
\hline No & $15.28(3847)$ & 1.00 & 1.00 & $1.46(4236)$ & 1.00 & 1.00 \\
\hline Yes & $41.80(122)$ & $3.19(2.42$ to 4.21$)$ & 3.27 (2.46 to 4.35$)$ & $7.35(68)$ & 5.18 (2.08 to 12.88$)$ & 5.94 (2.28 to 15.47$)$ \\
\hline
\end{tabular}

*Seroconversion from negative to positive over study duration.

tEducational status dichotomised to any schooling versus no education for syphilis. 0 woman with technical school or college had incident infection.

¥For religion 'other' category excluded from regressions because of sample size.

$\S$ Lifetime male sex partners dichotomised to multiple versus 0 or 1.0 woman who reported never having sex at baseline had syphilis.

ILifetime male sex partners excluded from final model because of collinearity with marital status.

${ }^{*}$ HSV-2-positive spouse included in HSV-2 model and syphilis-positive spouse included in syphilis model.

HSV-2, herpes simplex virus-2; IRR, incident rate ratio; N, total number of people (positive and negative) in category. 
Christian or Hindu religion, lower education and marital status. In the final combined model, only age, education and Muslim religion remained significantly associated. Of the health and behavioural associations found in the univariate analyses -circumcision alcohol use, lifetime sex partners and syphilisseropositive spouse-only spousal HSV-2 seropositivity remained statistically significant in the final combined model. Circumcision was associated with a lower incidence of HSV-2 in the risk model (incidence rate ratio (IRR) $0.74,95 \%$ CI 0.55 to 0.97 ) but was excluded from the final model because of collinearity with Muslim religion.

The model for syphilis in men showed slightly different characteristics. Although age was significant in the initial sociodemographic model, once the behavioural risk factors were included in the final combined model it was no longer statistically significant at any individual strata, but remained significant taken as a whole.

When compared with the male HSV-2 data, women had a few additional factors of importance. Similar to men, older age, lower education and HSV-2-positive spouse were significant in the univariate and final models. Additionally, in both univariate and final models, lower SLI score, field jobs and previously or currently married women were shown to be at higher risk. Unlike the male data, rural residence remained significant in the final model. Although syphilis seropositivity at baseline was associated with incident HSV-2 in the univariate and initial risk behaviour analyses, this association did not remain significant in the final combined model.

For women, the only sociodemographic variables that remained significantly associated with incident syphilis were increasing age and having no education. Of the behavioural factors in the risk model-tobacco use, multiple lifetime male partners and spousal syphilis seropositivity-only spousal HSV-2 seropositivity was significant.

For both STIs, baseline HIV positivity was examined as a risk factor for subsequent STI. Although higher rates were observed, the finding did not reach statistical significance (see online supplementary tables S1 and S2). However, incident HIV was significantly more likely to occur in participants with incident HSV-2 (IRR 3.98, 95\% CI 2.13 to 7.41 ) (data not shown).

\section{Seroconcordance/discordance}

Of the 2716 stably married couples, 2499 (HSV-2) and 2520 (syphilis) had complete data on the infection status of each partner (see online supplementary table S3). Estimating transmission probability we found that for HSV-2 infections in previously seronegative couples there was no difference between male and female acquisition of infection (19.4 vs 20.9 per 1000 couple-years, $\mathrm{p}>0.05$ ) (table 4).

There was a slight male predominance of outside infections for syphilis (3.1 vs 1.0 per 1000 couple-years, $\mathrm{p}<0.05)$.
Couples that were serodiscordant at baseline had markedly different transmission dynamics for HSV-2 and syphilis with estimated male-to-female vs female-to-male transmission of 193.3 vs 119.0 per 1000 couple-years for HSV-2 and 27.6 vs 198.8 for syphilis ( $\mathrm{p}<0.05$ for both).

\section{DISCUSSION}

To our knowledge, this is the first population-based report of HSV-2 and syphilis seroincidence from India. Overall we found seroincidence of HSV-2 and syphilis to be high relative to baseline prevalence. STI incidence was highest with HSV-2 among rural residents and specifically rural women. Two striking findings from this analysis are the consistent association of higher STI incidence with older age and rapid STI transmission among rural populations.

The pattern of higher incidence as age increases has also been reported in studies of HSV-2 seroincidence done in the USA and New Zealand, although these studies were in younger cohorts (32 and below). ${ }^{13}$ A few possible explanations of this phenomenon are as follows: (1) there is a higher seroprevalence as groups age that could confer a higher risk of partnering with someone with an active infection. One caveat to this hypothesis is that seroprevalence is not a clear marker of active infection. However, this cohort effect is made more likely by a greater lifetime risk of having multiple partners as one ages. (2) Younger couples that get married and live in joint family households (common practice in India) may gain more autonomy in their daily activities with age and seniority. They then may be able to pursue outside relationships that were not possible beforehand. (3) Public health messages on safe sex and STI prevention may have less penetrance in older populations. (4) There may be an increased biological susceptibility for HSV-2 and syphilis infection in older individuals.

Over a short 5.6-year period, a higher rural STI incidence has brought the previously lower rural vs urban prevalence of these STIs to equivalent levels. Higher prevalence in urban areas may precede a spread to the rural population. This may be mediated in part through migrant workers as they travel from cities and couple with rural partners. This hypothesis is supported by the association of incident STI with transport-related occupation that was found here and in previous work showing increased HIV risk behaviours and visits to sex workers among migrant workers. ${ }^{25}{ }^{26}$ Now that the prevalence has 'evened out' in rural and urban populations, it may be that the incidence rates will also begin to equalise. Other drivers of this association may be related to sociodemographic factors such as lower levels of education and religion. A lower level of education was the largest confounder of the rural-HSV-2 association and explained some of the increases seen here. Rural residents are also more likely to be Hindu or Christian, both groups with higher STI incidence compared with Muslims. Muslims are far more likely to be

Table 4 Estimated rates of sexually transmitted infection transmission in stably married couples

\begin{tabular}{|c|c|c|}
\hline & HSV-2 & Syphilis \\
\hline Male infection outside of couple* & 19.4 (16.6 to 22.5$)$ & $3.1(2.2$ to 4.2$)$ \\
\hline Female infection outside of couple* & $20.9(17.9$ to 24.1$)$ & $1.9(1.2$ to 2.9$)$ \\
\hline Male-to-female transmission within the couple* & 193.3 (153.7 to 238.2 ) & 27.6 (8.1 to 60.0$)$ \\
\hline Female-to-male transmission within the couple* & 119.0 (89.6 to 152.3$)$ & $198.8(108.2$ to 329.5$)$ \\
\hline Root-mean-squared error (RMSE) $\dagger$ & 18.1 & 2 \\
\hline
\end{tabular}


circumcised, which has been shown to be protective against STIs such as HSV-2, and may explain some of the effect seen here.

Although baseline HIV was not found to be a significant risk factor for either HSV-2 or syphilis incidence, our sample size was small (just 26 men and 22 women with HIV at baseline) and we were likely underpowered to detect true differences. In an exploratory analysis, we did find a roughly $4 \times$ higher rate of incident HIV in those with incident HSV-2. This supports multiple lines of evidence showing that active HSV-2 is a significant risk factor for HIV and highlights the importance of broader STI prevention. ${ }^{3-6}$ The rates of syphilis incidence were too low to allow an examination of its association with incident HIV.

In this study, previously married women had significantly higher rates of HSV-2 and higher absolute rates of syphilis compared with women that were currently or never married. While previous work consistently found higher prevalence in this group, ${ }^{19} 27$ our results provide the first temporal information about this association. It suggests that for many of these women STIs are contracted after a marriage ends and not before. This indicates that previously married women may occupy a place in society that leaves them more vulnerable to unsafe sexual practices and subsequent STI acquisition.

Our examination of the serodiscordance/concordance status of couples aids in our understanding of the dynamics of STI transmission. Previous work by Arora et al examined seroconcordance among Indian couples using prevalence data and found that in contrast to studies from South Africa, men were more likely than their spouses to be the first infected partner. ${ }^{17}{ }^{28}$ Our estimates suggest an equivalent rate of male vs female HSV-2 acquisition in seronegative couples, but higher rates of syphilis acquisition by the male partner. Similar to the Arora paper, our data support a higher risk of HSV-2 transmission from men-to-women vs women-to-men. The transmission dynamics were markedly different for syphilis, with a higher rate of transmission from women to men within couples. Past examinations of syphilis epidemiology have shown higher rates of incident cases in men, suggesting a component of differing transmission probabilities, but conclusive estimates have been elusive. ${ }^{29}$ Our data support a higher transmission probability of syphilis from women to men versus men to women. This may reflect a greater biological susceptibility in women and/or differences in sexual practices when the female versus male partner is infected.

There were several limitations to this study. The sample was limited to one district in the state of Andhra Pradesh, and especially given the geographic heterogeneity of STI prevalence in India, our findings may not be generalisable to India as a whole. A $67 \%$ follow-up rate makes it possible that the sample that remained was subject to compositional bias. In particular, those with HIV at baseline were less likely to participate in the follow-up study, indicating that some of the highest risk participants may have dropped out. However, in other cases, there were lower participation rates in individuals with factors associated with decreased STI incidence (ie, higher education).

The HSV-2 assay used has been shown to have varied performance in different populations, ${ }^{20} 30{ }^{31}$ although this was taken into account when determining the index cut-offs, and quality control testing against gold standard western blot was performed. The validity of these data is also supported by the similar patterns seen in both syphilis and HSV-2 results. Lastly, HSV-2 may also be contracted orolabially leading to seroconversion. This type of transmission may be particularly prevalent among women participating in childcare. Although orolabial HSV-2 transmission would reflect true infection, this is largely clinically irrelevant in terms of HIV risk.
In conclusion, these data show a changing epidemic, in which older persons, rural populations and women are relatively more vulnerable to incident HSV-2 and syphilis. These trends suggest a need to reorient STI prevention strategies to include messaging and programmes targeted to populations previously thought to be at lower risk of infection.

\section{Key messages}

- Incidence of herpes simplex virus-2 (HSV-2) and syphilis over a 5-year period was high relative to baseline prevalence.

- Risk of incident HSV-2 and syphilis increased with age.

- Rural women and previously married women were at the highest risk of incident HSV-2.

- HSV-2 transmission was more likely from men to women while syphilis transmission was more likely from women to men.

\section{Handling editor Jackie A Cassell}

Contributors LD and RD conceived and led this population-based cohort study. JAS, VL, GAK and MAlary contributed to the design. MAkbar, GMMA and SPR supervised the field data collection. VL led the laboratory analysis and TS contributed to this. CHH, JAS and BA did the statistical analysis. CHH and JAS wrote the initial draft of the paper. All authors contributed to interpretation of findings and approved the final version of the paper.

Funding This work was supported by the US National Institutes of Health under award numbers R01Al084315 and R21HD068352, and by a grant from the Bill \& Melinda Gates Foundation. The content in this publication is solely the responsibility of the authors and does not necessarily represent the official views of the National Institutes of Health or the Bill \& Melinda Gates Foundation.

None of the authors have any relevant conflicts of interest to report.

\section{Competing interests None.}

Ethics approval The protocols, procedures and analyses for this study were approved by institutional ethics committees of the Public Health Foundation of India, Nizam's Institute of Medical Sciences, the Centre hospitalier affilié universitaire de Québec and the University of Chicago.

Provenance and peer review Not commissioned; externally peer reviewed.

Open Access This is an Open Access article distributed in accordance with the terms of the Creative Commons Attribution (CC BY 4.0) license, which permits others to distribute, remix, adapt and build upon this work, for commercial use, provided the original work is properly cited. See: http://creativecommons.org/ licenses/by/4.0/

\section{REFERENCES}

1 Ray K, Bala M, Gupta SM, et al. Changing trends in sexually transmitted infections at a Regional STD Centre in north India. Indian J Med Res 2006;124:559-68.

2 Kumar B, Sahoo B, Gupta S, et al. Rising incidence of genital herpes over two decades in a sexually transmitted disease clinic in north India. J Dermatol 2002;29:74-8.

3 Tobian AA, Quinn TC. Herpes simplex virus type 2 and syphilis infections with HIV: an evolving synergy in transmission and prevention. Curr Opinion HIV and AIDS 2009:4:294-9.

4 Reynolds SJ, Risbud AR, Shepherd ME, et al. Recent herpes simplex virus type 2 infection and the risk of human immunodeficiency virus type 1 acquisition in India. J Infect Dis 2003;187:1513-21.

5 Reynolds SJ, Risbud AR, Shepherd ME, et al. High rates of syphilis among STI patients are contributing to the spread of HIV-1 in India. Sex Transm Infect 2006;82:121-6.

6 Arora P, Nagelkerke NJ, Jha P. A systematic review and meta-analysis of risk factors for sexual transmission of HIV in India. PloS ONE 2012;7:e44094.

7 Becker ML, Ramesh BM, Washington RG, et al. Prevalence and determinants of HIV infection in South India: a heterogeneous, rural epidemic. AIDS 2007;21:739-47.

8 Jennings JM, Louis TA, Ellen JM, et al. Geographic prevalence and multilevel determination of community-level factors associated with herpes simplex virus type 2 infection in Chennai, India. Am J Epidemiol 2008;167:1495-503.

9 Schneider JA, Lakshmi V, Dandona R, et al. Population-based seroprevalence of HSV-2 and syphilis in Andhra Pradesh state of India. BMC Infect Dis 2010;10:59. 
10 Sgaier SK, Mony P, Jayakumar S, et al. Prevalence and correlates of Herpes Simplex Virus-2 and syphilis infections in the general population in India. Sex Transm Infect 2011;87:94-100.

11 Madhivanan $\mathrm{P}$, Chen YH, Krupp K, et al. Incidence of herpes simplex virus type 2 in young reproductive age women in Mysore, India. Indian J Pathol Microbiol 2011;54:96-9.

12 Kumarasamy N, Balakrishnan P, Venkatesh KK, et al. Prevalence and incidence of sexually transmitted infections among South Indians at increased risk of HIV infection. AIDS Patient Care STDS 2008:22:677-82.

13 Page WF, Chubb M, Feng $X$, et al. National estimates of seroincidence and seroprevalence for herpes simplex virus type 1 and type 2 among US military adults aged 18 to 29 years. Sex Transm Dis 2012;39:241-50.

14 Dickson N, van Roode T, Herbison P, et al. Risk of herpes simplex virus type 2 acquisition increases over early adulthood: evidence from a cohort study. Sex Transm Infect 2007;83:87-90.

15 Dandona L, Lakshmi V, Sudha T, et al. A population-based study of human immunodeficiency virus in south India reveals major differences from sentinel surveillance-based estimates. BMC Med 2006;4:31.

16 Dandona L, Dandona R. Drop of HIV estimate for India to less than half. Lancet 2007;370:1811-13.

17 Arora P, Nagelkerke N, Sgaier SK, et al. HIV, HSV-2 and syphilis among married couples in India: patterns of discordance and concordance. Sex Transm Infect 2011;87:516-20.

18 Dandona L, Kumar GA, Lakshmi V, et al. HIV incidence from the first population-based cohort study in India. BMC Infect Dis 2013;13:327.

19 Dandona L, Dandona R, Kumar GA, et al. Risk factors associated with HIV in a population-based study in Andhra Pradesh state of India. Int J Epidemiol 2008;37:1274-86.

20 LeGoff J, Mayaud P, Gresenguet G, et al. Performance of HerpeSelect and Kalon assays in detection of antibodies to herpes simplex virus type 2. J Clin Microbiol 2008;46:1914-18.

21 Schmidt BL, Edjlalipour M, Luger A. Comparative evaluation of nine different enzyme-linked immunosorbent assays for determination of antibodies against
Treponema pallidum in patients with primary syphilis. J Clin Microbiol 2000;38:1279-82.

22 Gordis L. Epidemiology. Philadelphia, PA: Elsevier/Saunders, 2009:116-18.

23 Zou G. A modified poisson regression approach to prospective studies with binary data. Am J Epidemiol 2004;159:702-6.

24 Victora CG, Huttly SR, Fuchs SC, et al. The role of conceptual frameworks in epidemiological analysis: a hierarchical approach. Int J Epidemiol 1997;26:224-7.

25 Saggurti N, Verma RK, Jain A, et al. HIV risk behaviours among contracted and non-contracted male migrant workers in India: potential role of labour contractors and contractual systems in HIV prevention. AIDS 2008;22:S127-36.

26 Dude A, Oruganti G, Kumar V, et al. HIV infection, Genital symptoms and sexual risk behavior among Indian truck drivers from a large transportation company in South India. J Glob Infect Dis 2009;1:21-8.

27 Walters K, Dandona R, Walters LC, et al. Wives without husbands: gendered vulnerability to sexually transmitted infections among previously married women in India. AIDS Care 2012;24:1103-10.

28 Lurie MN, Williams BG, Zuma K, et al. Who infects whom? HIV-1 concordance and discordance among migrant and non-migrant couples in South Africa. AIDS 2003;17:2245-52.

29 Garnett GP, Aral SO, Hoyle DV, et al. The natural history of syphilis. Implications for the transmission dynamics and control of infection. Sex Transm Dis 1997;24:185-200.

30 Ashley-Morrow R, Nollkamper J, Robinson NJ, et al. Performance of focus ELISA tests for herpes simplex virus type 1 (HSV-1) and HSV-2 antibodies among women in ten diverse geographical locations. Clin Microbiol Infect 2004;10: 530-6.

31 Nascimento MC, Ferreira S, Sabino E, et al. Performance of the HerpeSelect (Focus) and Kalon enzyme-linked immunosorbent assays for detection of antibodies against herpes simplex virus type 2 by use of monoclonal antibody-blocking enzyme immunoassay and clinicovirological reference standards in Brazil. J Clin Microbiol 2007:45:2309-11. 


\section{Correction}

Hochberg CH, Schneider JA, Dandona R, et al. Population and dyadic-based seroincidence of herpes simplex virus-2 and syphilis in southern India. Sex Transm Infect 2015;91:375-82.

This article has published with an incorrect open access license statement. The correct license statement is:

This is an Open Access article distributed in accordance with the terms of the Creative Commons Attribution (CC BY 4.0) license, which permits others to distribute, remix, adapt and build upon this work, for commercial use, provided the original work is properly cited. See: http://creativecommons.org/licenses/by/4.0/

Sex Transm Infect 2018;94:235. doi:10.1136/sextrans-2014-051708corr1

D Check for updates 